\title{
An archaeological textile from the Monastery of Pombeiro: between conservation and perception
}

\author{
Marijke de Bruijne ${ }^{1}$ \\ Paula Monteiro ${ }^{2, *}$ \\ ${ }^{1}$ Independent textile conservator, Eindhoven, The Netherlands \\ 2 José Figueiredo Laboratory (LJF), Directorate General for Cultural Heritage (DGPC), Rua das Janelas Verdes \\ 1249-018, Lisbon, Portugal \\ *pmonteiro@dgpc.pt
}

\begin{abstract}
Fragments of an archaeological textile were found in 2005 during the excavations of St. Mary Monastery of Pombeiro, Portugal. Investigation and conservation treatment took place in the textile department at José Figueiredo Laboratory (LJF) belonging to the Directorate General for Cultural Heritage (DGPC), in Lisbon. The textile is composed of several fragments. Despite the poor condition, metal threads are discernible. The purpose of this article is to reveal the mount, which was developed with a dual function: display and storage. Conserving the fragments and improving its appearance was a double target previously defined. The methodology employed requirements for conservation treatment and careful selection of materials will be disclosed.
\end{abstract}

Têxtil arqueológico do Mosteiro de Pombeiro:

entre a conservação e a perceção

\section{Resumo}

Durante as escavações, que decorreram em 2005, no Mosteiro de Santa Maria de Pombeiro, Portugal, foram encontrados fragmentos de um têxtil arqueológico. $O$ estudo e o tratamento de conservação foram realizados no Laboratório José de Figueiredo (LJF), em Lisboa, sob a alçada da Direcção Geral do Património Cultural (DGPC). O têxtil é composto por vários fragmentos; apesar do mau estado de conservação, são visíveis fios metálicos. O objectivo deste artigo é divulgar o suporte de acondicionamento realizado com dupla função: exposição e reserva. Foi previamente definido um duplo objectivo que consistia em conservar os fragmentos e melhorar a sua perceção. É divulgada a metodologia empregue assim como os requisitos estipulados para o acondicionamento e a seleção criteriosa de materiais.

\section{Keywords}

Archaeological textile

Mounting

Exhibition

Storage

Pattern

\section{Palavras-chave}

Têxtil arqueológico

Acondicionamento

Exposição

Reserva

Padrão 


\section{Introduction}

In 2005 the archaeologist Dr. Ricardo Erasun Cortés discovered some textile fragments during the excavations in the St. Mary Monastery of Pombeiro (also called Monastery of Pombeiro) in the Municipality of Felgueiras, located $14 \mathrm{~km}$ South East of the town Guimarães in the North of Portugal. The monastery is one of the oldest institutions in Portugal, being first mentioned in the year 853 [1-2]. Based on the geological stratification layers in which the textile fragments were found, they can be dated back to the 16th century. Nothing is known about what kind of object the fragments originally were part of. Contemporary sources mention the burial of the nobility in the monastery, so maybe the fragments were part of costume or ecclesiastical vestments. Yet, there are many other possibilities, so this is purely hypothetical.

The object was carried to the textile department at José Figueiredo Laboratory (LJF) in Lisbon, for study purposes and treatment. In 2009 the fragments were investigated at the LJF in collaboration with the Faculty of Sciences and
Technology (FCT NOVA), Campus of Caparica, by master student Joana Domingues [3].

In this article, the type of mount carried out for these archaeological fragments, the methodology, requirements for conservation treatment and the materials used will be described.

\section{Object}

The textile fragments consist of four bigger pieces of 11 $\mathrm{cm}$ long, between 2.5 and $9.5 \mathrm{~cm}$ wide and between 0.2 and $0.5 \mathrm{~cm}$ high. Furthermore, there are five little pieces having the largest $5 \mathrm{~cm}$ in length, $3 \mathrm{~cm}$ in wide to $0.6 \mathrm{~cm}$ high and the smallest $3 \mathrm{~cm}$ in lenght to 2 wide to $0.2 \mathrm{~cm}$ high, further a group of very tiny fragments (Figure 1). Though the fragments are small, it is possible to distinguish two different fabrics, composed of rich materials. The technical analysis allowed the fragments to be included in the category "textile bearing surface decoration" [4, p. 34]. The ground fabric is a silk lamé appliqued with a silk velvet, outlined with

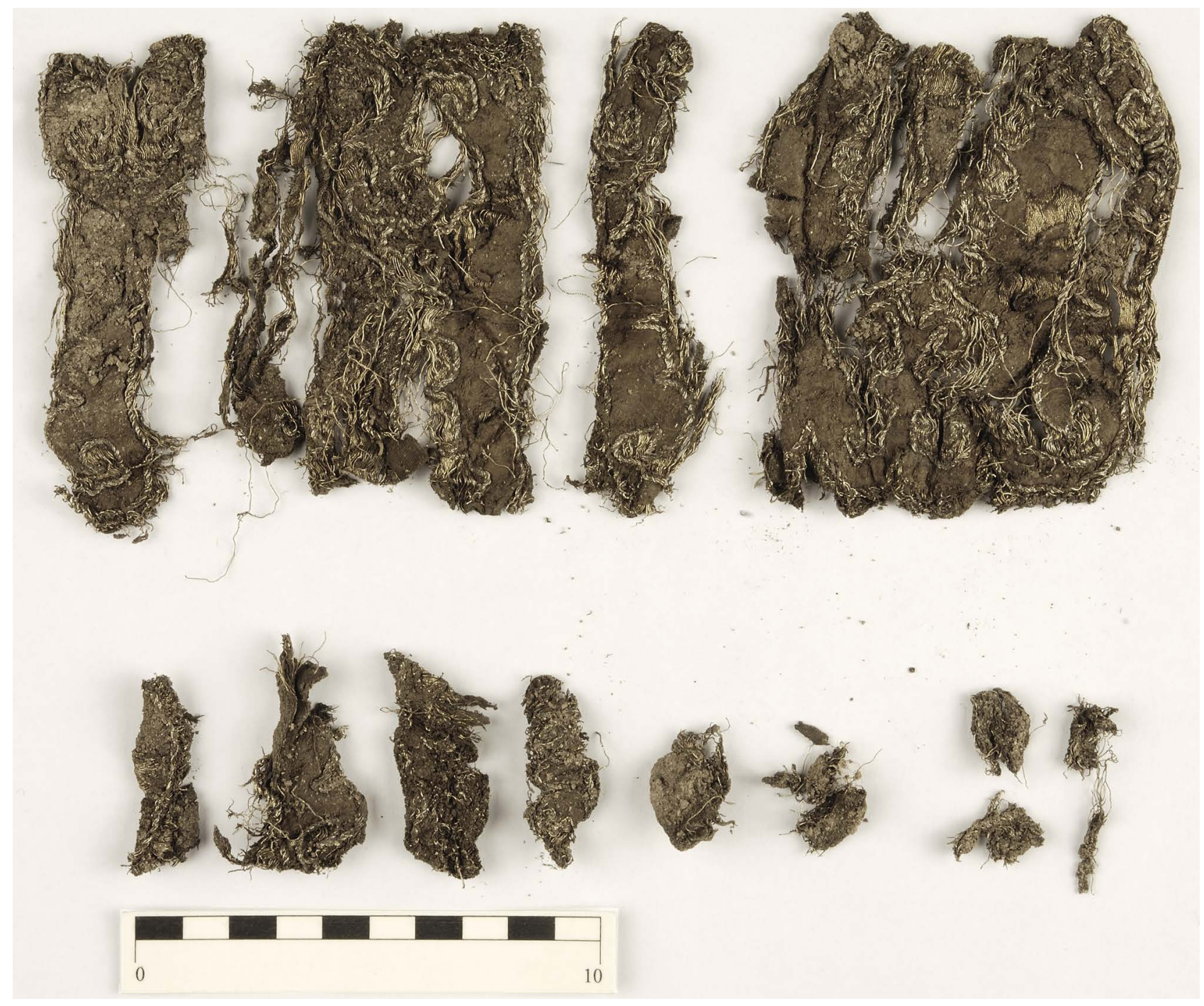

Figure 1. Archaeological fragments of the St. Mary Monastery of Pombeiro, Felgueiras, Portugal. Photo: Jorge Horácio (LJF/DGPC). 
couched cord of gilded silver threads. The lamé consists of two warps and three wefts. The mains warp and weft work in satin 5; the binding warp fixed the pattern weft in twill ( 3 tie 1 ) and the supplementary weft in twill (2 tie 2). This weft is composed of gilded silver strips wound around silk core. The velvet consists of two warps and one weft. The mains warp and weft work in twill (3 tie 1 with 6 threads), three picks to one rod. This cut velvet has a long pile which allows to be denominated plush [5, p. 39]. The twisted cord used for outlining consists in two separated strands, each one composed of five metal threads made up of gilded silver strips wound around a silk core.

The lamé was woven with silk threads and highlights the gilded silver threads on the surface, which would have made it a brilliantly shining weave. This lamé is decorated with applications of cut velvet with a long pile, edged with an applied cord of twisted gilded silver threads (Figure 2). In this archaeological textile, all the metal threads identified belong to the typology of "metal strip wound around a core of animal fibres yarn" [6], thus gilded silver strip, wrapped around a core of silk fibres [3, p. 6-8].
The stereo zoom microscopy Leica MZ 12.5, enlargement $100-200 \times$, combined with photographic techniques (visible and X-ray) were fundamental for revealing that the applications were organized in a way to create stylised vegetal motifs; together they form a continuous pattern.

\section{Condition}

The colour of the object is unclear; the brown colour it has today is very typical for archaeological textiles and is probably not the original colour. The main reason for the discolouration of archaeological textiles is probably the immersion of the objects, which leads to the dissolution of the dyes [7]. No research has been executed into the original colours. The biggest fragments have a rectilinear sharp edge on one side (Figure 3 ). This edge looks like it has been cut. It is unclear when or why this is done.

The fragments are very fragile and brittle. The silk fibres break off and the fragments lose material easily when touched or moved.

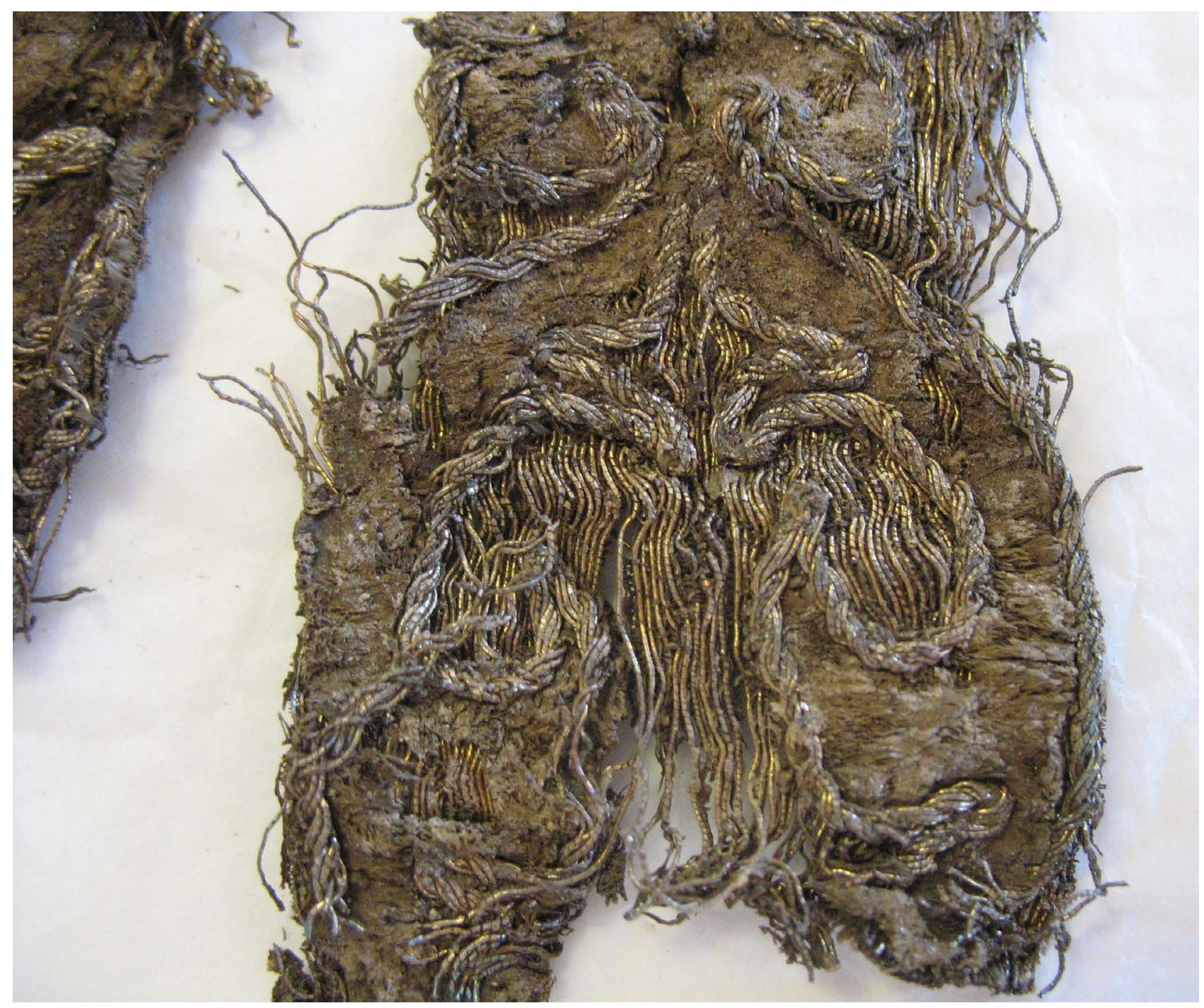

Figure 2. Detail of a fragment, metal threads used as a cordon in applied decoration. 


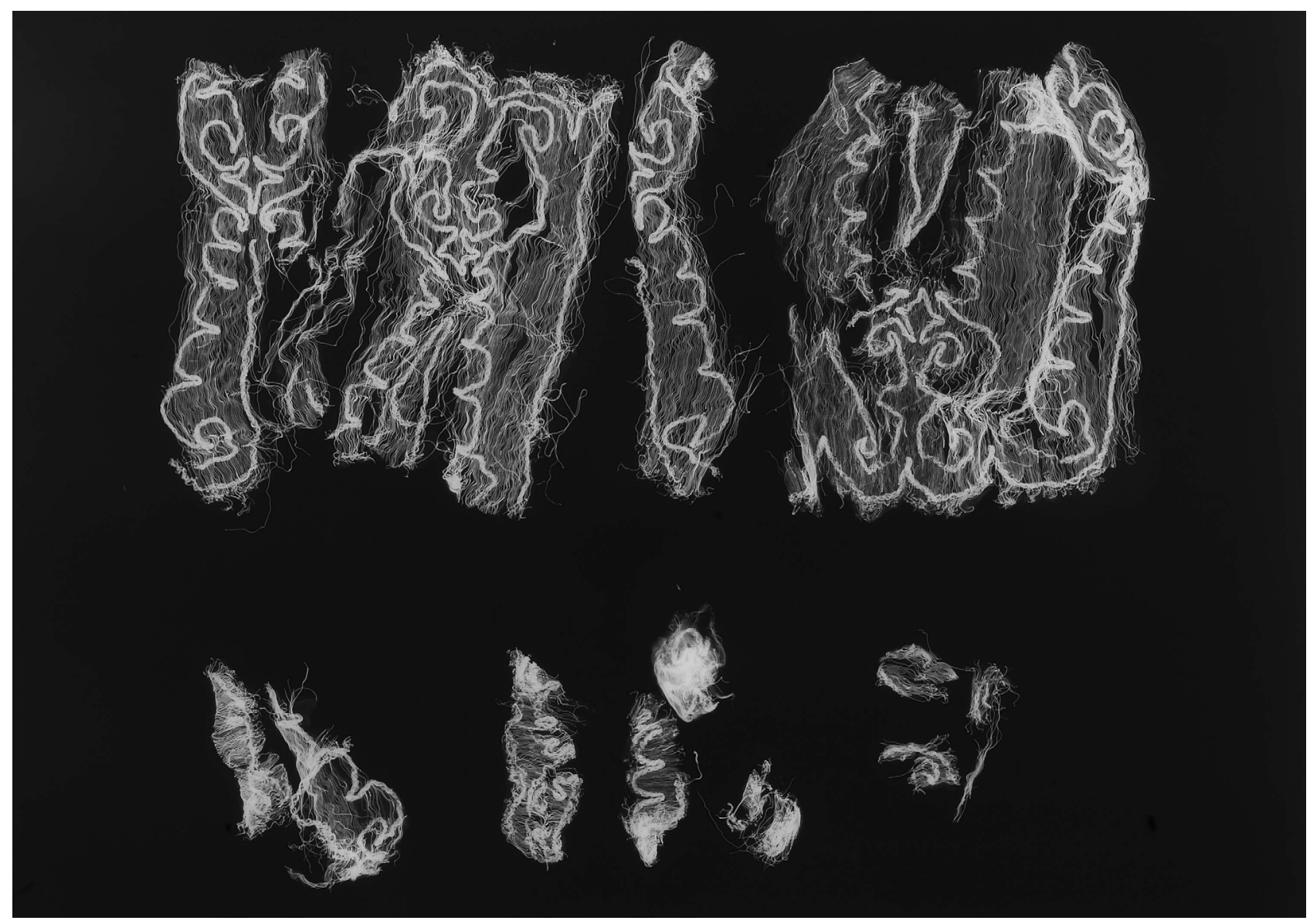

Figure 3. X-radiograph of the archaeological textile fragments. Photo: Jorge Horácio (LJF/DGPC).

It is not surprising that specifically the fragments with applications are the ones best preserved: this overlay layer make those fragments stronger. Though the metal threads of the lamé maintain some structure, the velvet applications were fundamental in preserving some of the stability, with its dense weave and its stitched contours.

In 2009 the fragments were cleaned with a micro vacuum cleaner, Bresciani micro aspirator, under a stereo zoom microscope, Leica MZ 12.5, enlargement 100-200×. The physical and chemical integrity of the fabric was not compromised during the cleaning treatment. The soiling accumulated in the interstices of the weaving could not be removed completely. The fragments still contain dirt, apparently layers of heavy soiling, also in the form of crystals lying loosely on the surface. For some fragments, a polyester film tents combined with the ultrasonic humidifier Esprit U1000 were used. The humidifying process allowed reducing some folds and the slow drying flattening gradually the fragments with the aid of stainless insect pins.

\section{Finding the pattern}

The applications with the contours of metal thread make a continuous pattern, which was clearly revealed by X-ray investigation, performed by the Photo Studio of LJF (Figure 3). Based on the X-radiograph, two main motifs, complementing each other, were identified. This allowed to present a proposal pattern and consequently to manage the organization of the fragments.

\section{Conservation and perception}

The textile fragments were extremely vulnerable. Furthermore, the lamé and the velvet which form a continous pattern are almost illegible. For those reasons it was desirable not only to stabilize the fragments, but also to make them more legible. A mount for the fragments had to be designed, for which the following set of objectives was formulated:

- stabilize the object;

- protect the object;

- respect the integrity of the object ;

- maintain study possibilities;

- no handling needed;

- display possibilities;

- legibility of the object;

- pleasing to the eye.

The goals and demands for the mount of the archaeological fragments were processed in a table (see Table 1). Every possible solution for a mount could be checked easily by using this table. 
One more important thing had to be taken into consideration when designing a mount. After mounting, the fragments will be returned to the Monastery of Pombeiro. This is not a museum with an ideal environmental control system and professional heritage keepers, the main risks being: no stable climate, humidity fluctuations and no basic knowledge of textile collection care, resulting in careless handling of the object. This had to be kept in mind when designing the mount.

\section{Objectives}

For stabilizing and protecting the object, prevention of any movement in the object is pivotal. This could be obtained by creating a rigid, non-slippery support.

To respect the integrity of the object, any intervention into the object itself had to be avoided. Preserving the integrity of the fragments' three-dimensionality is of great importance.

To maintain study possibilities it was desirable to view the object from all sides and from very close by, without blurring the view or contact with the object.

To prevent direct handling of the object, the mount should be suitable not only for storage, but for display as well, and should allow the fragments to be moved easily and safely.

The legibility of the object means to clarify the object itself to the viewer, as well as the fabrics, the threads, the materials, the ornaments and the decorative patterns. It is unknown from what kind of object these fragments originate; however it would be interesting and

\section{Table 1}

Evaluation of the goals for mounting of the archaeological textile fragments from the Monastery of Pombeiro

\begin{tabular}{lc} 
Goals & $\begin{array}{c}\text { Resulting mount for the } \\
\text { archaeological fragments }\end{array}$ \\
\hline Rigid support, stabilizing & + \\
\hline Protection & + \\
\hline Integrity of the object & + \\
\hline Handling of the object & + \\
\hline Study possibilities & + \\
\hline Display possibilities* & + \\
\hline Legibility & + \\
\hline Pleasing to the eye & + \\
\hline
\end{tabular}

+ Positive; - Negative

* The main fragments have limited study possibilities, but some tiny fragments are left behind for this purpose

informative to make the decorative pattern more visible and understandable to the viewer.

The objective that the mount must be pleasing to the eye is a somewhat difficult goal, because it is difficult to describe what is pleasant and what is not. However, a careful selection of the type and colours of the materials, based on the compatibility and reversibility, and an execution as neatly as possible, are essential in order to preserve and highlight the object.

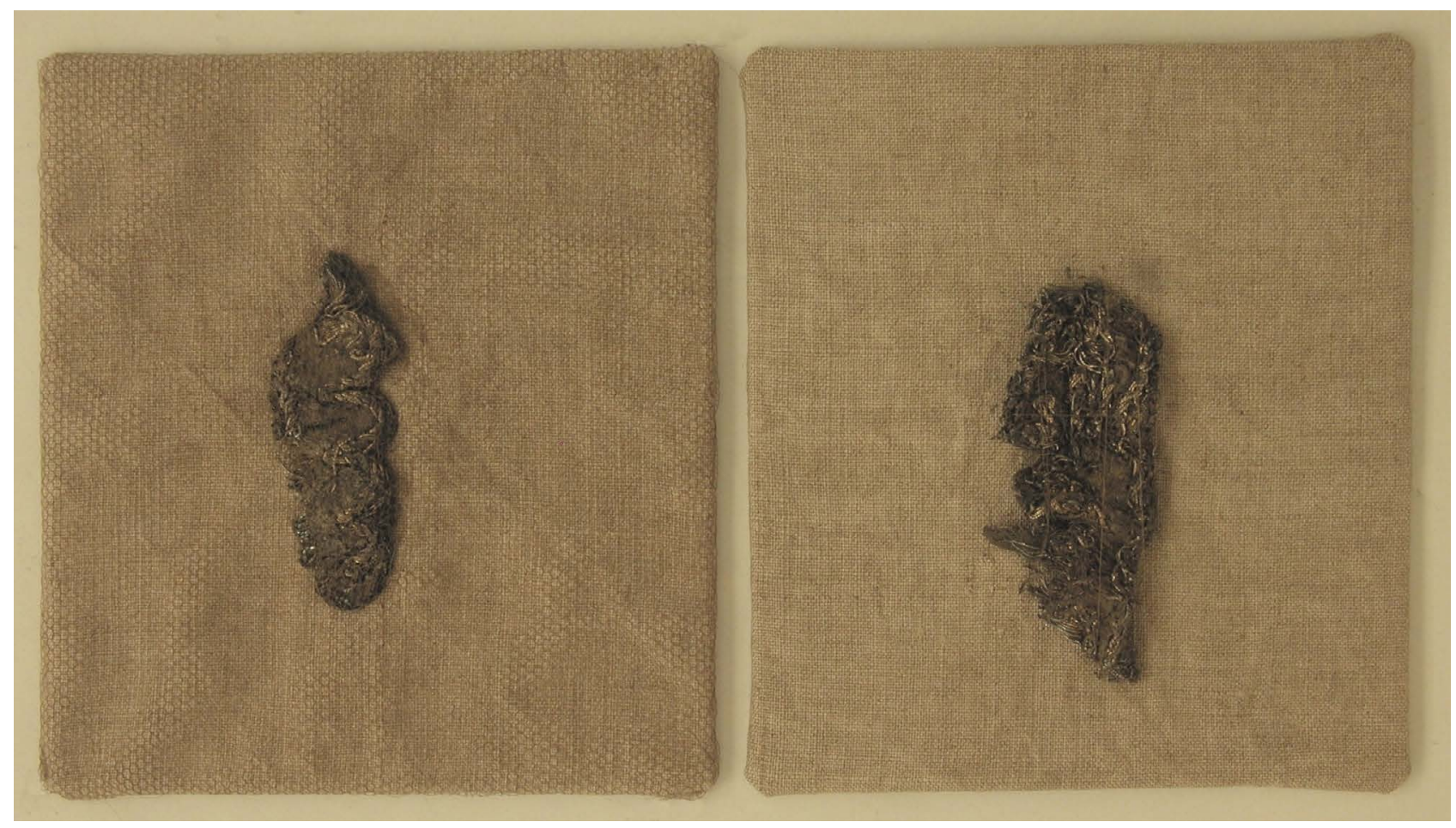

Figure 4. The mounting proposals executed by Joana Domingues: fragment fixed with nylon net (left); fragment fixed with a grid of threads (right). 


\section{Designing the mount}

For the mount design, earlier solutions for mounting archaeological fragments were studied, in particular:

- The first mounting proposal of two little fragments of the Monastery of Pombeiro by Domingues in 2009 [3, p. 13-14]. Both fragments were fixed in two different ways on a rigid support, covered with a linen fabric. One fragment was fixed with nylon net and the other with a grid of threads (Figure 4). Those solutions were not found satisfying: in the first case, the observation of the fragment is disturbed by the surrounding area, while in the second case the grid attachment does not confer stability and protection to the fragment.

- The mounting of a series of archaeological fragments from the tomb of archbishop Dom Gonçalo Pereira ( $\dagger 1384$ ), belonging to the Tesouro - Museu da Sé de Braga (Portugal) [8]. Some of the fragments are on display in that museum. The mounting was found to be very satisfactory; it meets all the set goals. The objects lie loose in a cutout, hollow form which holds the object in place, without the need to fix it. A lid over the mount, in which the form of the object is also cut out, makes it possible to turn over the objects and see the object on both sides. The lid can be taken off and put on display. The objects are stable, the mount is suitable for storage and for display, the objects have good visibility and study possibilities and the mounts are very pleasing to the eye.

However, looking at the fragile condition of the fragments from the Monastery of Pombeiro, and also keeping in mind that the fragments will go back to the Monastery, where no professional caretaker is present, another solution had to be found for these fragments. The goal of stabilizing the fragments was found to have more priority than the goal to have optimum study possibilities. Thus, the possibility of manipulating the fragments to observe the reverse side was soon eliminated and a protection with nylon net would be inevitable and the appropriate solution to ensure the stability and protection of this textile.

All fragments were documented and photographed before, during and after treatment. The documentation is kept in the archives of LJF in Lisbon [9]. A study and treatment report is delivered to the proprietary together with the object, according to the rules established in LJF.

\section{Build-up in layers}

On the base of the set goals and with the examples in mind, a mount was designed for the textile fragments of the Monastery of Pombeiro, consisting of the following five layers (Figure 5):

- Prevention of any movement in the object could be obtained by creating a rigid support. This support is made of corrugated plastic sheet. This prevents movement and direct handling of the object.

- The rigid mount is covered with a soft layer of cotton flannel. The fragments are placed directly on the flannel. The flannel is soft and prevents sliding of the fragments.

- The fragments are fixed with nylon (polyamide) net. The nylon net will be fixed with stitches closely around the fragments. Not only does this fix the fragments, it also offers protection.

- A layer of nylon felt of $0.3 \mathrm{~cm}$ thickness, with the shapes of the fragments cut out. This protects the fragments all around. It also hides the nylon net around the fragments, thus making the nylon net less obvious. This layer is fixed with stitches on the flannel of the rigid mount.

- A second layer of nylon felt $(0.3 \mathrm{~cm})$, with not only the shapes of the fragments but also the pattern design cut out. This will make a suggestion of a continuous pattern around the fragments, which may clarify the pattern of the fragments to the viewer. This layer is made detachable by using cotton ribbons with Velcro on the four corners of the mount (Figure 5). This gives the opportunity to view and show the fragments also without the suggestion of the pattern design. The ribbons with Velcro can be fixed on the bottom side when this layer of felt is taken off. This will prevent the ribbons getting lost when the second layer of felt is not being used and it results in a kind of legs under the rigid support, which will elevate the mount slightly from the ground.

\section{Execution of the mount}

\section{Selecting the materials}

For the rigid support, a white sheet of corrugated polypropylene was chosen. This remains straight and with
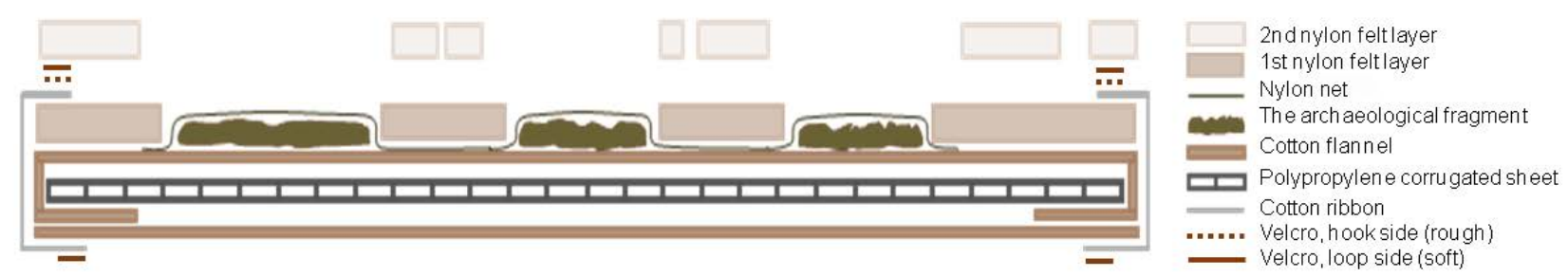

Figure 5. Scheme mounting profile. 


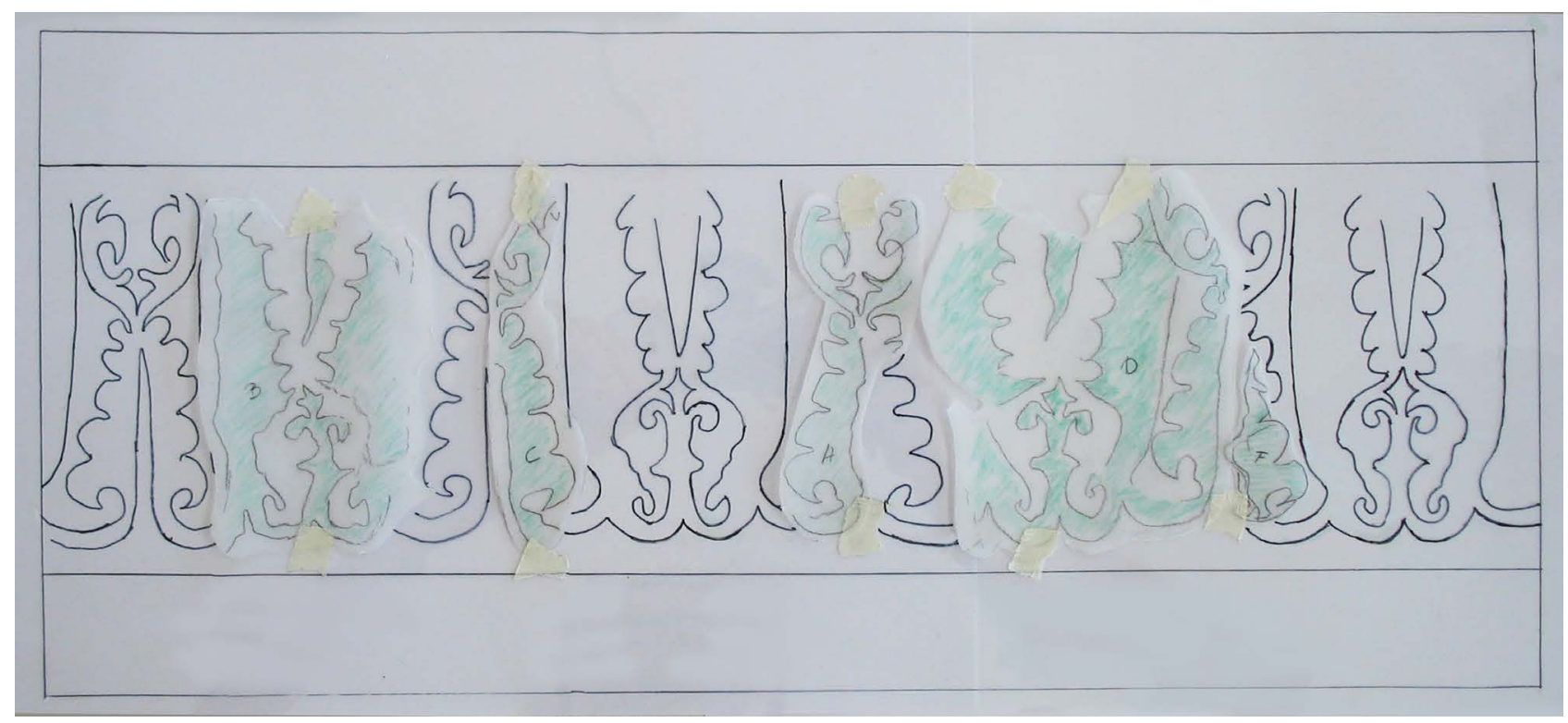

Figure 6. Final arrangement of the fragments (in green pencil) on the pattern design.

the ability to repel water, it does not bend or get soft in moist conditions. For the cover of this support a sturdy white cotton flannel was chosen. A soft nylon (polyamide) net was used to cover and protect the fragments. A nylon felt of $0.3 \mathrm{~cm}$ thickness was chosen for the next two layers of the mount. Nylon is not susceptible to insect attack, which makes it a better choice than woollen felt. A cotton ribbon was used for attaching the second felt layer. For fixing the nylon net a silk thread was used. To make the stitches hardly visible, this proved to be the best option from the available materials. A stronger polyester thread was used for attaching the first felt layer to the mount. The goal was to assemble all the different materials using no adhesives, so needle stitching by hand was chosen. All materials needed were available in the textile department of LJF.

\section{Dyeing the materials}

First step in the execution of the mount was dyeing the materials. To establish the right colours, first some samples were dyed. On the base of this testing, the dye baths were prepared. The flannel was washed before with Lissapol, an anionic surfactant [6, p. 196]. The dyeing was executed with Dylon Textile Dye. Dylon is used in LJF for over 20 years for dyeing support materials and found to be stable over time.

The cotton flannel was coloured in a neutral beige colour, much lighter than the colour of the fragments, but not too contrasting. The nylon net was dyed dark brown, matching the colour of the fragments, to make the nylon net almost invisible when put over the fragments. The first layer of nylon felt was dyed beige, matching the colour of the flannel, as were the cotton ribbon for the Velcro and the silk threads for fixing the nylon net. The second layer of felt was dyed in a somewhat different colour, a light grey. Though a quite neutral colour in its own, this contrasts somewhat more with the fragments than the beige. All pieces of material were left overnight to dry.

\section{Arranging the fragments on the reconstructed pattern}

For the optimal arrangement of the fragments, the proposal pattern based of the X-ray, was used as a starting point. This reorganisation obviously contains details and deformations from the original textile fragments that were slightly attenuated to make the design straighter, symmetrical and clean. The two main motifs were drawn only once and arranged into a continuous pattern on a straight line, then traced on Melinex, resulting in a new clear pattern. This was fundamental to consider the organization of the fragments for the mounting.

Subsequently, the different fragments were arranged into this reconstructed pattern. It is not known how the different fragments originally were exactly placed in relation to each other; therefore, the arrangement of the fragments is just a proposal. Several arrangements were tried. The original fragments were not used for this, they are too fragile to be moved around; so, the forms of the fragments were traced on paper from the X-ray. The chosen arrangement was thought to make the pattern in the fragments most visible and clear (Figure 6).

Only the four larger fragments and one smaller fragment could be placed into the reconstructed pattern. For the four other small fragments, it was totally unclear from what part of the pattern they could originate; without references it was not possible to fit them into the pattern. So, it was decided to leave them out and make a second mount for the four remaining little fragments, without a reorganisation of the pattern around those fragments. 


\section{Rigid board and flannel}

The rigid board of corrugated polypropylene was cut into the right size with an $\mathrm{X}$-acto knife. The dimensions of the mount $(20.5 \mathrm{~cm} \times 44.5 \mathrm{~cm})$ were defined according to the size occupied by the fragments, already organized in the pattern proposal. These dimensions were calculated to leave a frame around the fragments with the dimensions of $5 \mathrm{~cm}$ on top and bottom margin, and 6 and $7 \mathrm{~cm}$ for the left and right side margin, respectively.

The mount was covered with the cotton flannel, fixed on the back with double sided conservation tape of $1.9 \mathrm{~cm}$ wide. The corners were cut and sewn. The back was finished with the same flannel, sewn all around with an overhand stitch. All sewing was done with a curved needle and a beige polyester thread.

\section{Cotton ribbons with Velcro}

Before proceeding with the mounting and fixing of the fragments, four pieces of beige dyed cotton ribbon, of about $10 \mathrm{~cm}$ long, were fixed on the back of the mount. Their function is to hold the second layer of felt. Two pieces of Velcro were fixed on both ends of the ribbons with a sewing machine. To avoid hard pulling, very tiny pieces of Velcro were used. The end of the four ribbons with the loop side (soft) of the Velcro was sewn by hand on the back of the covered mount. An extra line was sewn where the ribbons can be folded back, to fit exactly when the ribbons are fixed on the back.

\section{Mounting the fragments and fixing with nylon net}

After deciding on the definite arrangement of the fragments in the pattern, the outlines of the original fragments were traced on Melinex, transferred to pattern paper, cut and integrated into the pattern design. This pattern design with the integrated fragments was used to make a new paper pattern in which the shapes of the fragments were cut out. This was used as a guide for arranging the fragments on the mount and afterwards for cutting the two layers of felt.

With the help of the paper pattern, the fragments were put exactly in place on the mount. Nylon net was placed over it and pinned temporarily (Figure 7). The nylon net

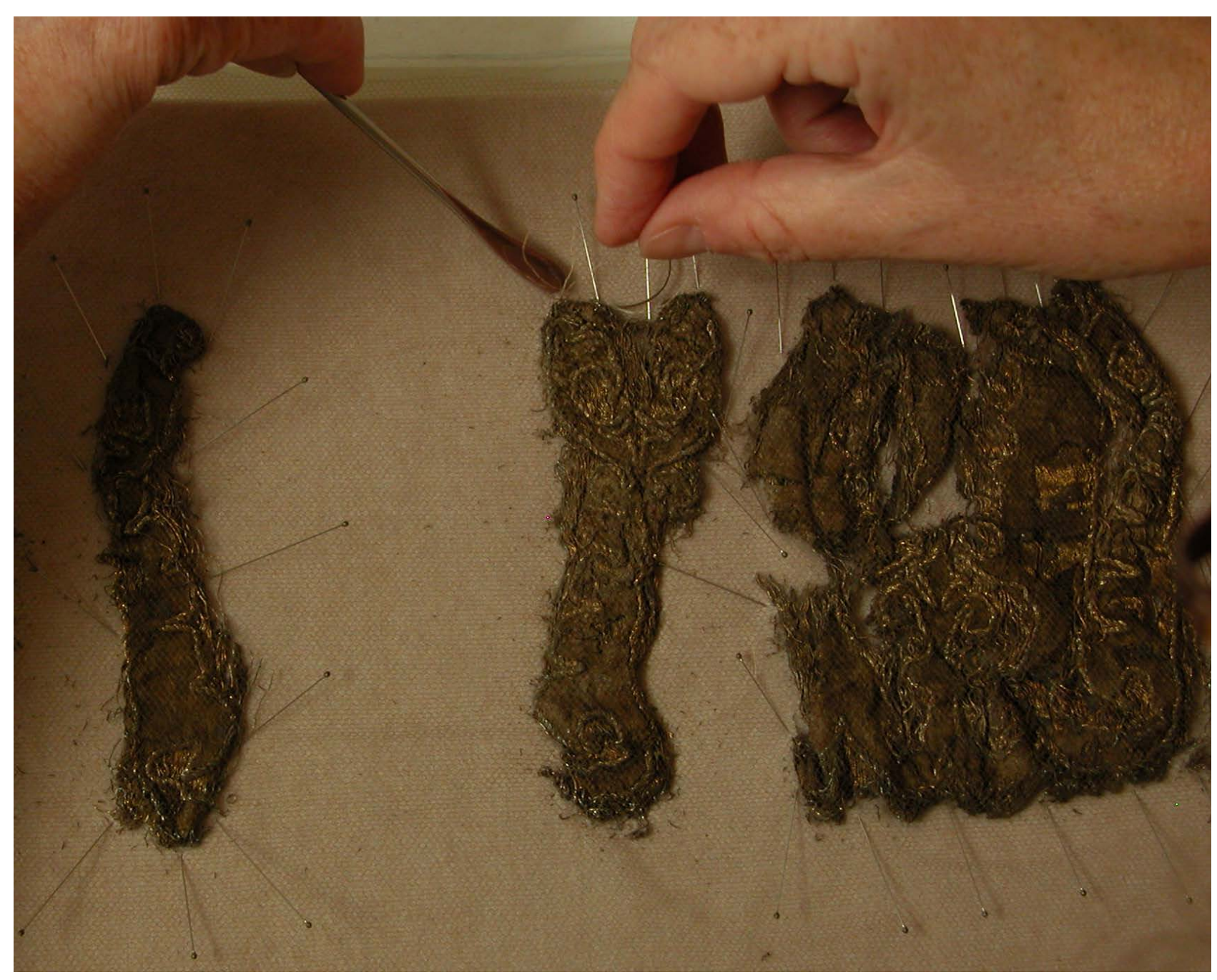

Figure 7. Pinning and sewing the nylon net around the fragments. 


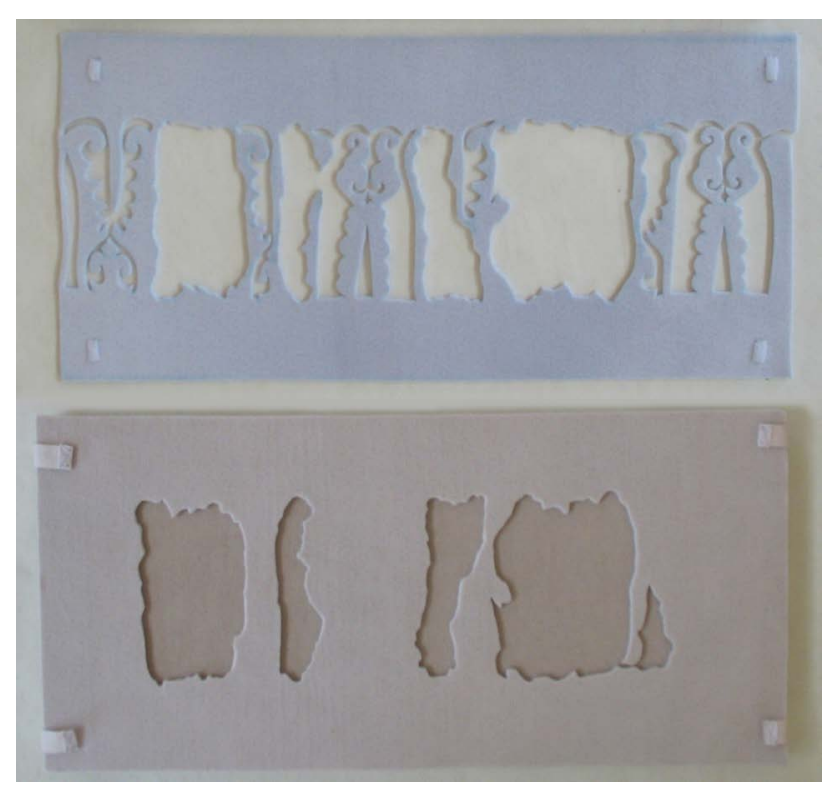

Figure 8. Attachment of the second layer of felt with Velcro.

was fixed in the flannel, closely around the fragments, with little backstitches. In holes in the fragments also some stitches were made, because it was necessary to hold the insecure fragments and also to pull the nylon net closely over the fragments. When nylon net is connected closely on the object, it is less visible. The nylon net was then cut, pinned and fixed all around with a running stitch.

After fixing the fragments the mount was vacuum cleaned around the fragments with a micro vacuum cleaner, to take away all loose particles that came of the fragments.

\section{Felt layers with fragment shapes cut out}

The two felt layers were cut into the size of the mount after covering the board with flannel, to make sure the sizes correspond exactly.

With the help of the paper pattern, the outlines of the fragments, arranged as decided, were copied on the two layers of felt, with a sewing pencil. This was done on the back, because it was not possible to remove the pencil traces completely. The cutting was executed with small sharp scissors. The shapes of the fragments were cut out of both layers of felt. The space required to prevent crushing or stressed fragments is created, but it also ensures protection by surrounding the fragments.

The first layer of felt was invisibly stitched around all sides on the flannel, with the beige polyester thread.

\section{Felt layer with the proposal pattern}

On the base of the proposal pattern, a second paper pattern was made in which the pattern design was cut out (Figure 8). This was used to cut out the second layer of felt, the grey one.

After cutting the pattern design out of the grey felt, it turned out that the felt was not rigid enough to maintain its stability. When put over the mount, partially loose parts had to be placed by hand. This was not satisfactory. To overcome this, it was decided to fix a piece of silk crepeline on the back of the felt. A silk crepeline of natural colour was dyed beige with Dylon Textile Dye to match the colours of the mount. The crepeline was cut away out around the fragments, not to obstruct the

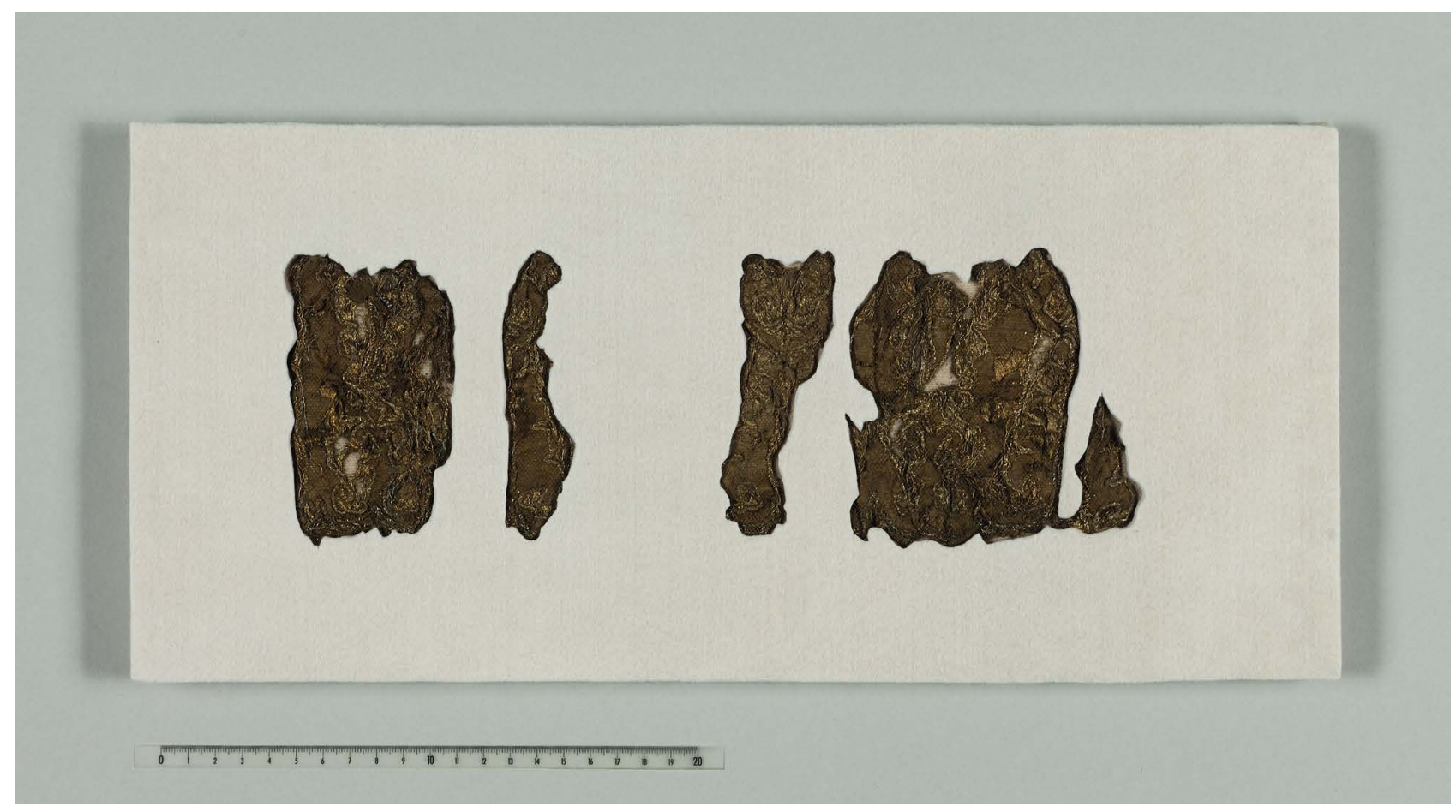

Figure 9. The resulting mount without the proposal pattern. Photo: Jorge Horácio (LJF/DGPC). 


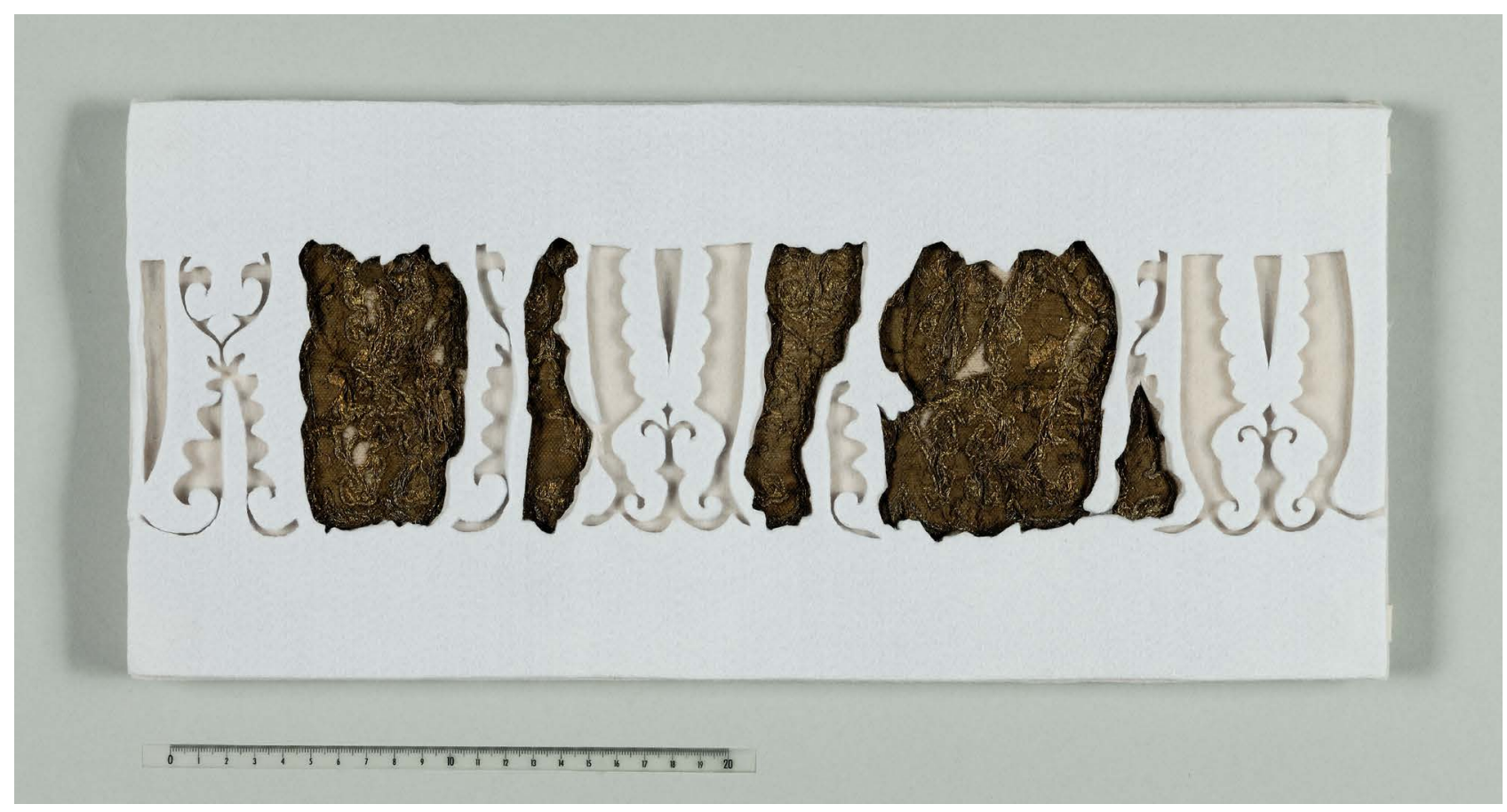

Figure 10. The resulting mount with the removable proposal pattern. Photo: Jorge Horácio (LJF/DGPC).

view on the object. To deal with this fraying fabric, lines of $4 \%$ Tylose MH $300 \mathrm{P}$ (methyl hydroxyethyl cellulose) were applied with a small painting brush, following the outlines of the fragments. Cutting was done along these lines; the adhesive prevents fraying of the edges.

The crepeline was pinned and then stitched by hand on the back of the felt with white silk thread, following the shapes of the fragments and the design.

Four soft pieces of Velcro were sewn by hand on the back of the second layer of felt. This makes it possible to attach this layer of felt to the mount by means of the cotton ribbons with Velcro.

\section{Other fragments}

The four little fragments that had to be left out of the pattern proposal were fixed on a second mount in the same way, but without the second layer of felt. A left over from the dyeing was used for this purpose, which was a lighter shade of beige.

The very tiny fragments are not mounted, but kept aside in a little sachet of acid-free paper. They can be used for future study purposes.

\section{Made-to-measure box}

For the main mount, the second mount with the little fragments and the tiny fragments, a made-to-measure acid-free cardboard box with a lid will be made. This box shall have three compartments where each of the objects fits in exactly. This way the three objects will be kept together in a simple, but safe and nice way. A piece of acid-free paper will be added to cover the objects.

\section{Result and discussion}

The resulting mount for the archaeological fragments of the St. Mary Monastery of Pombeiro was found to be quite satisfying (Figures 9-10). Most of the goals set in the beginning of the project were reached (Table 1). The fragments are stabilized and safely stored, which was the main goal. The fragments are made more legible by revealing the pattern around it. This makes look closer for the continuation of the pattern in the fragments. The chosen materials and colours work well; the look and feel of the mount is good. Instead of looking dark, dull and dirty, the result looks attractive, fresh and pleasant. All this makes the mount very suitable for presentation. The mount offers several display possibilities: the main fragments can be shown with or without the proposal pattern and the little fragments may or may not be shown together with the main fragments. In addition to the above, the mount can be shown horizontally but can be raised for ease of viewing, never exceeding $45^{\circ}$, with no ill effect.

Some compromises had to be made in reaching the goals. Due to the extreme fragility of the fragments, and considering the circumstances where the fragments will be kept (in a monastery, not in a museum), it was decided to compromise on the study possibilities. The fragments are fixed under nylon net, so the detail examination must be executed through the nylon net and they cannot be studied on the reverse. However, study is still possible on the tiny fragments which are not mounted.

Fixing the fragments with the nylon net was a very rewarding task, because it was very clear that finally the fragile fragments were secured. No movement in the 


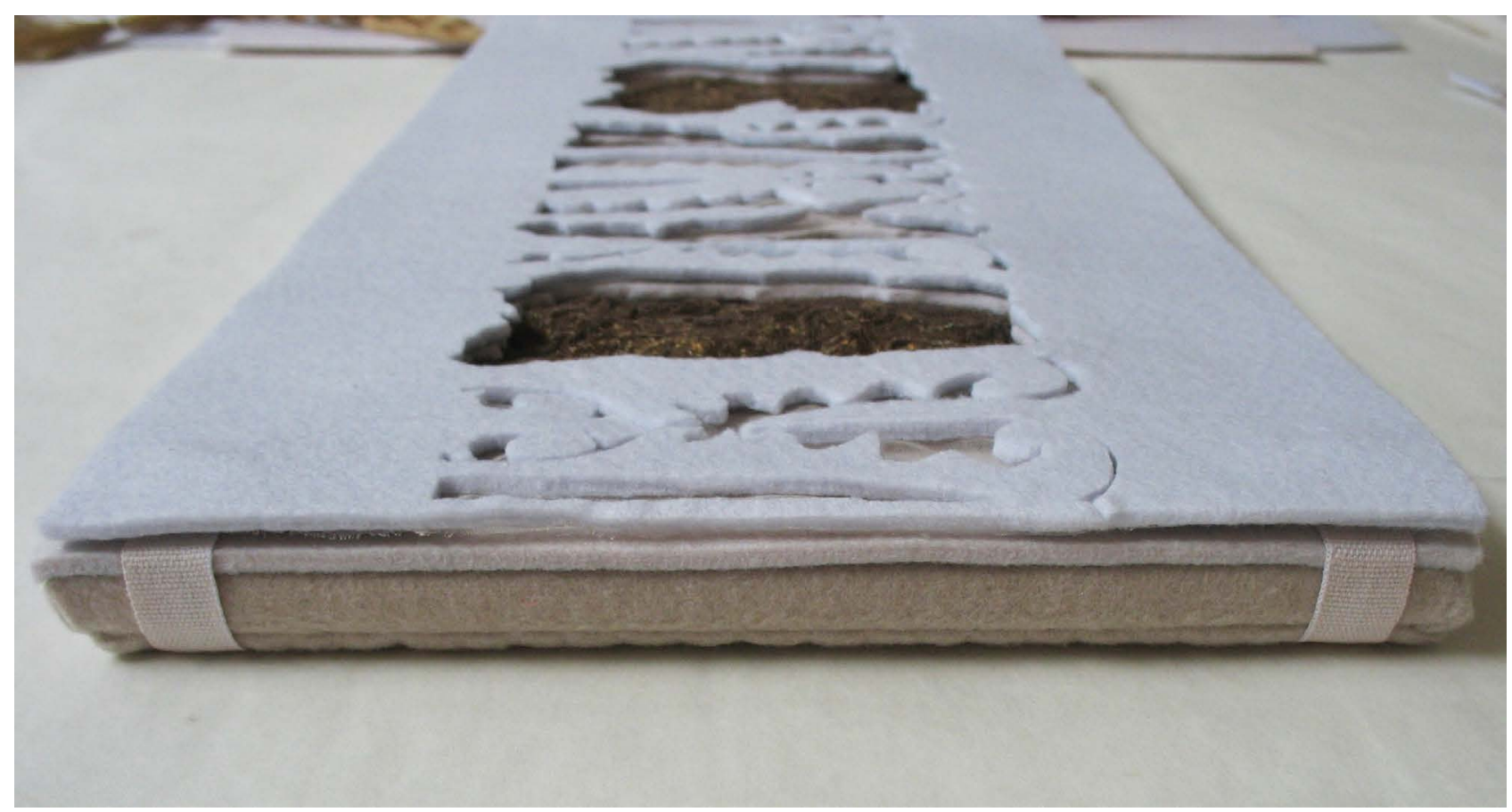

Figure 11. The resulting mount profile with the several layers.

fragments is possible anymore, which will prevent more loss of material.

\section{Function of the several layers}

The various layers (Figure 11) have a function in stabilizing and protecting the object: the rigid mount prevents movement of the object; the flannel gives it a soft ground and at the same time avoids sliding of the fragments; the nylon net keeps the fragments fixed without intervention into the object itself, offers protection and prevents movement of the fragments. The first felt layer gives the fragments a soft protection all around, making them completely embedded in this layer. The materials and beige colours of the flannel and felt work well with the fragment: it is neutral, in a tint that is comparable to the object, it is not too dark and not too light. The first felt layer also helps to hide the nylon net, which is hardly visible and not experienced as an obstruction to the view on the object.

The detachable second layer of felt is revealing the pattern, but also gives extra protection to the fragments. Furthermore, this layer was designed to provide a new reading of this archaeological textile. The grey of this felt has a kind of lavender blueish shade. This colour works well with the fragments: it contrasts with the fragments without attracting too much attention and it looks as if the gold is shining more (Figure 12).

\section{Some critical notes}

In the second layer of felt, some problems in the execution were faced. Once cut, the felt turned out to be not rigid enough to maintain stability. Silk crepeline attached to the back did help to give it back some stability, and when put over the mount the crepeline is not visible. But it was difficult to attach the crepeline neatly to the felt, especially on the short edges of the mount, and it did cost a lot of time. Another solution would have been to fix the layer with stitches on the first layer, but then this layer would not have been detachable and thus presentation possibilities would have been limited. In retrospect this problem could have been prevented by keeping a frame of felt around the whole pattern design, not only on the top and lower side, but also on both lateral sides.

The arrangement of the fragments into the pattern is just a proposal; it is not known how the fragments originally were placed in relation to each other. It was not

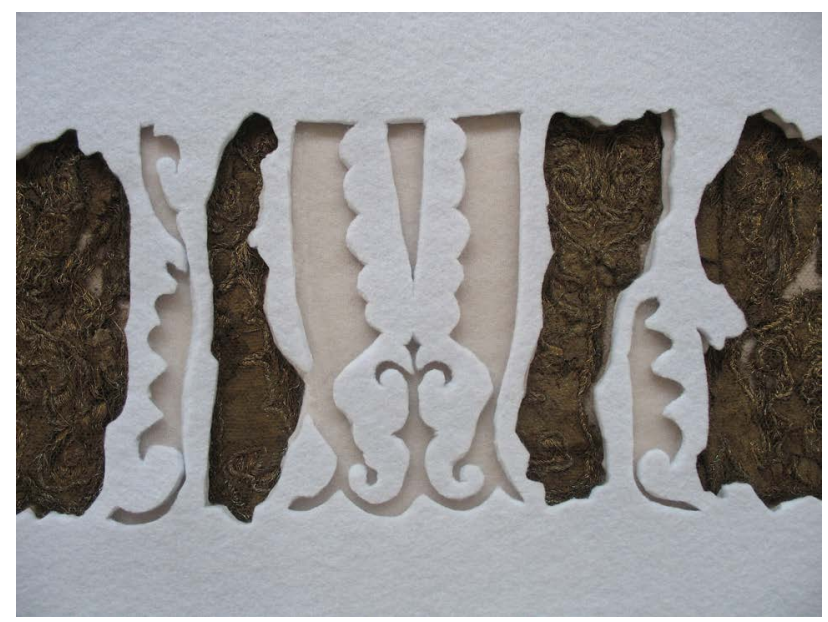

Figure 12. Detail of the resulting mount. 
possible to fit four of the little fragments into this pattern. Therefore, it was decided to leave them out of the pattern design and fix them on a separate mount, without the second layer of felt.

\section{Conclusion}

For the treatment of these archaeological fragments of the Monastery of Pombeiro, a double target was set beforehand: to conserve the object and to achieve better perception of the object. Both targets are achieved satisfactorily. The resulting mount optimizes the stabilization and protection of the fragments; it ensures the double function of storage and display and offers legibility of the decorative pattern of the object. All this is accomplished with respect to the integrity of the object. Compromises had to be done on the study possibilities, but by keeping the tiny fragments aside, study opportunities are ensured. The object can be returned safely to its keeper, the St. Mary Monastery of Pombeiro in Northern Portugal. So, the conditions to develop further studies of this fragment are created and a possible correlation with the other excavated objects, from the same archaeological stratification layer, would also be interesting.

\section{Acknowledgments}

In the whole process of thinking and reconsidering all wishes, problems and possible solutions, it was found very fruitful and indispensable to exchange ideas and work closely together with our colleagues. Therefore, we would like to thank the colleagues from LJF and especially Luis Pedro (conservation technician, LJF) and Madalena Serro (independent textile conservator), who both were always very willing to add to the discussion. The process of designing the mount therefore was a truly cooperative production. The authors wish to acknowledge Direção Regional de Cultura de Lisboa e Vale do Tejo and Direção Regional de Cultura do Norte, Portugal, for providing the opportunity to investigate and to perform the conservation intervention of the archaeological textile.

\section{List of materials}

- Polypropylene corrugated sheet $(1 \mathrm{~cm})$ : Mitera, Agualva Cacém, Portugal

- White cotton flannel: Tecidos Santo Condestável, Lisboa, Portugal

- Nylon felt $(0.3 \mathrm{~cm})$ : Nomalism, Lisboa, Portugal

- Nylon (polyamide) net: Dukeries Textiles \& Fancy Goods Ltd , Nottingham, United Kingdom

- Silk crepeline: Whaleys (Bradford Ltd), Bradford, United Kingdom

- Cotton ribbon: Retrosaria Adriano Coelho, Lisboa, Portugal

- White Velcro: Retrosaria Adriano Coelho, Lisboa, Portugal

- Polyester thread Gütermann: Retrosaria Adriano Coelho, Lisboa, Portugal
- Silk thread: Pura Seda, pura-seda@homail.com, Vila Nova de Gaia, Portugal

- Dylon Textile Dye: http://www.dylon.nl

- Lissapol, anionic surfactant: SETA, Lda (extinct), Porto, Portugal

- Tylose (methyl hydroxyethyl cellulose): Preservation Equipment Lda, Norfolk, United Kingdom

- Conservation ATG Tape Permanent (double sided), pH7-70: R\&C Restaurar \& Conservar, Lisbon, Portugal http://www.restaurarconservar.com

- Melinex (polyester film, 100 micron): Preservation Equipment Ltd, Norfolk, United Kingdom

- Micro vacuum cleaner Muntz: Bresciani, Milano, Italy http://www.brescianisrl.it

\section{References}

1 'Mosteiro de Santa Maria de Pombeiro', in Direcção Regonal da Cultura do Norte, http://www.culturanorte. $\mathrm{pt} / \mathrm{pt} /$ patrimonio/mosteiro-de-santa-maria-de-pombeiro/ (accessed 2018-5-14).

2 'Mosteiro de Pombeiro / Igreja do Mosteiro de Santa Maria de Pombeiro', in Sistema de Informação para o Património Arquitetónico, http://www.monumentos.pt/Site/APP PagesUser/SIPA.aspx?id=4864 (accessed 2018-5-14).

3 Domingues, J., 'Estudo e intervenção de conservação e restauro - Fragmento arqueológico', relatório de Projecto II, Universidade Nova de Lisboa - Faculdade de Ciências e Tecnologia, Costa da Caparica, Departamento de Conservação e Restauro (2009).

4 Landi, S., The Textile Conservator's Manual, 2ed, ButterworthHeinemann, Oxford (1992).

5 Vocabulaire Français, Centre International d'Étude des Textiles Anciens, Lyon (2005).

6 Tímár-Balászy, A.; Eastop, D., Chemical Principles of Textile Conservation, Butterworth-Heinemann, Oxford (1998).

7 Cybulska, M.; Maik, J., 'Archaeological textiles - A need for new methods of analysis and reconstruction', Fibres \& Textiles in Eastern Europe 15(5-6) (2007) 185-189.

8 Monteiro, P.; Serro, M.; Barbosa, F.; Carvalho, G., 'Urdir para acondicionar: Elaboração de suportes para os fragmentos têxteis pertencentes a Dom Gonçalo Pereira ', in IX Jornadas da Arte e Ciência UCP - V Jornadas ARP. Homenagem a Luís Elias Casanovas. A Prática da Conservação Preventiva, ed. R. C. Borges, E. Vieira \& J. C. Frade, Universidade Católica Editora, Porto (2014) 151-164.

9 'Processo TO-1, processo de restauro n. ${ }^{\circ}$. 005/08', report, Laboratório José de Figueiredo, Lisboa.

Received: 2018-6-12

Revised: 2018-11-27

Accepted: $2019-1-15$

Online: $2019-3-1$

(C)

This work is licensed under the Creative Commons Attribution-NonCommercial-NoDerivatives 4.0 International License. To view a copy of this license, visit http://creativecommons.org/licenses/by-nc-nd/4.0/deed.en. 